\title{
Modern Electrical Power Source on New System of Dissipation and Renewable Energies Sources
}

\author{
Zygmunt Szymanski \\ Institute of Electrical Engineering and Process Control in Mines, Silesian University of Technology Gliwice, Gliwice 44-100, Poland
}

\begin{abstract}
This paper presents some solutions of modern renewable energy system applied actually in dissipation energy source: wind turbine, solar panel battery charge, SSS (support set system), and standby diesel generator cooperated in series, parallel and hybrid system with main energy system. Its solution enable obtain independent individual energy source in different work exploitations. One of problems concerned with alternative energy source is changes of output voltages and output power dependence of climatic conditions. Possible solution is application of decoupled adjustable speed generation system in renewable energy generation. The decoupled generation system consists of: alternative energy source, internal combustion engine drives permanent magnet generator and DC/AC, or AC/AC converter. Performance of single decoupled generation set is discussed supported by results of laboratory tests. To provide high quality voltage is applied an additional energy storage, made from super capacitor and bidirectional DC/DC convert. Such system performs very stiff voltage in any load condition. Integration of solar battery panels or renewable wind energy system is provided via DC link of the variable speed decoupled autonomous generation system. Results of computer simulation and laboratory experiments are presented in the paper.
\end{abstract}

Key words: Power source, renewable energy, dissipation.

\section{Introduction}

Renewable energy sources have non stable nature and their available power and energy are practically not predictable. However, their average potential energy is high and they will be important source of energy in different part of world. Variation of available power of renewable energy source results in poor quality of delivered energy. Therefore to utilize energy, produced by the wind tower, and a solar battery charges, a power conditioners are applied. In case of source producing electricity, the most common system is connecting them to stiff grid or to parallel operating generating set that provides quality AC voltage. Other method of renewable energy quality improvement is application of energy storage as battery or super capacitor bank. To

Corresponding author: Zygmunt Szymanski, D.Sc., research fields: wheel vehicle and rail vehicle drive system, modern diagnostic system of vehicle. E-mail: Zygmunt.Szymanski@polsl.pl. provide high quality energy by hybrid system energy storage ratio of installed renewable source power to rated load power should be very high and energy storage capacity should be great. Moreover, in case of longer break of renewable energy recharging energy storage may be a problem. Therefore, the parallel operated conventional power source, including synchronous generator driven by internal combustion engine, is common practice. In conventional generating systems refueling is provided at any time and takes short time. Generator is sized to rated power of the load, and power produced by renewable source reduces theoretically demand of the primary energy delivered by drive to generator. As the generating set efficiency drops significantly with loads, then primary energy savings are engine driving the generator. Most of saved energy by renewable energy source application is dissipated by this additional load. The paper presents some solutions of modern renewable energy system 
applied actually in dissipation energy source: wind turbine solar panel battery charge, SSS (support set system), and standby diesel generator cooperated in series, parallel and hybrid system with main energy system. Its solution enable obtain independent individual energy source in different work exploitations. The paper proposes decoupled variable speed generating system application as energy saving power conditioning method which also provides high quality delivered power and assures long life cycle of the engine. The decoupled generation system consists of alternative energy.

\section{Islanding Supply System}

Islanding refers conditions in which a distributed generator continues to power a location, even though electrical grid powers from the electric are designed to supply power to the grid, are generally required to have some sort of automatic anti-islanding circuitry in them. In intentional islanding, the generator disconnects from the grid, and forces the distributed generator to power the local circuit [1]. It can be dangerous to workers, who may not realize that a circuit is still powered, and it may prevent automatic re-connection of devices. For that reason, distributed generators must detect islanding and immediately stop producing power; this is referred to as anti-islanding. The common example of islanding is a grid supply line that has solar panels attached to it. In the case of a blackout, the solar panels will continue to deliver power as long as brightness is sufficient.

In this case, the supply line becomes an "island" with power surrounded by a "sea" of unpowered lines. For this reason, solar inverters that backup system for buildings that normally sell their excess power to the grid. Islanding basics electrical inverters are devices that convert direct current to alternating current. Grid-interactive inverters have additional requirement that they produce AC power that matches the existing power presented on the grid. In particular, a grid-interactive inverter must match the voltage, frequency and phase of the power line it connects to. There are numerous technical requirements to the accuracy of this tracking. Consider the case of a house with an array of solar panels on the roof. Inverter(s) attached to the panels convert the varying DC current provided by the panels into AC power that matches the grid supply. If the grid is disconnected, the voltage on the grid line might be expected to drop to zero, a clear indication of a service interruption. However, consider the case when the house's load exactly matches the output of the panels at the instant of the grid interruption. In this case the panels can continue supplying power, which is used up by the house's load. In this case there is no obvious indication that an interruption has occurred. Normally even when the load and production are exactly matched, the so-called "balanced condition" the failure of the grid will result in several additional transient signals being generated. For instance, there will almost always be a brief decrease in line voltage, which will signal a potential fault condition. However, such events can also be caused by normal operation, like the starting of a large electric motor. Methods that detect islanding without a large number of false positives are the subject of considerable research. Each method has some threshold that needs to be crossed before a condition is consider to be a signal of grid interruption, which leads to a NDZ (non-detection zone), the range of conditions where a real grid failure will be filtered out. New standard solution is the state of the art automatic disconnection device, which guarantees that inverters in the grid have a very high availability, and can easily adapt to all grid conditions. Fig. 1 presents a SMA plant control system which enable an automatic control and monitoring PV plan, and Fig. 2 presents scheme of energetic island configuration system. This paper places a statistical data of renewable sources: solar power, wind energy, hydroelectric power stations and their participation in general energy balance. It demands settlements of connected regulations with: production, energy transfer, and with the recuperation 


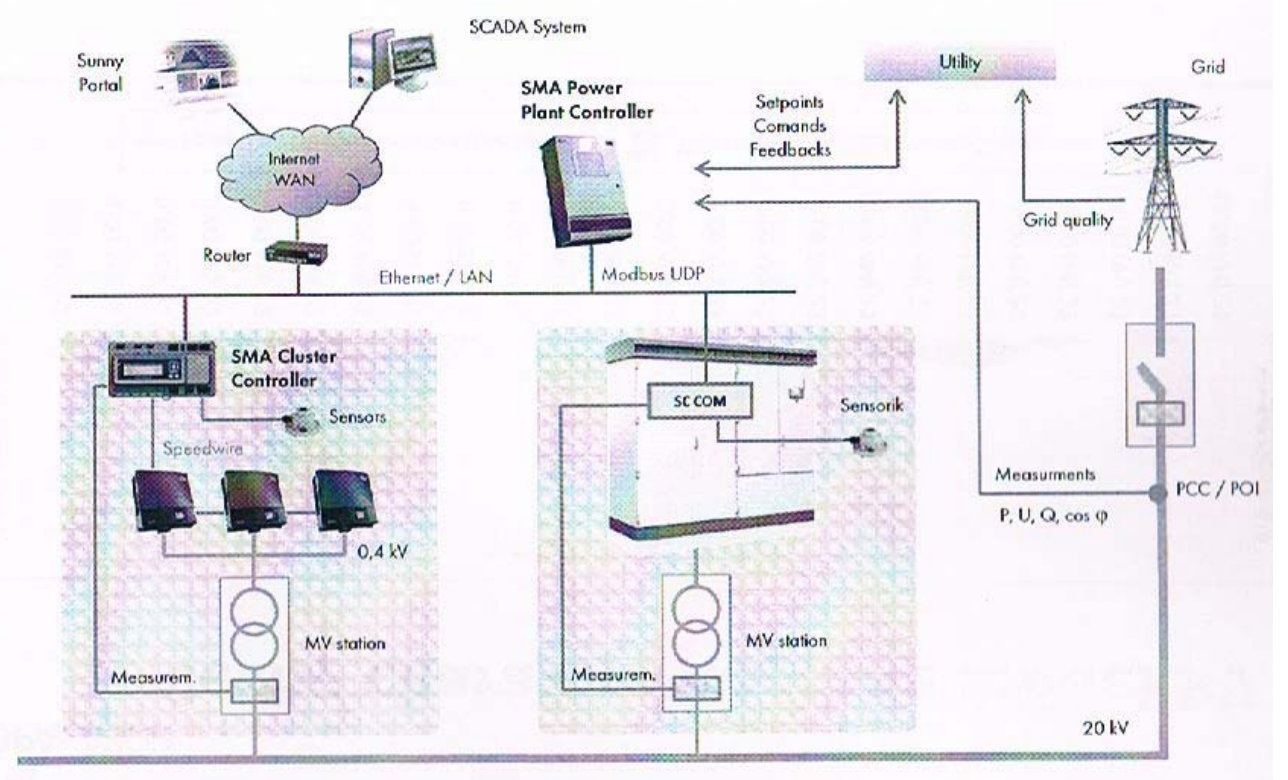

Fig. 1 SMA plant control system [2, 3].

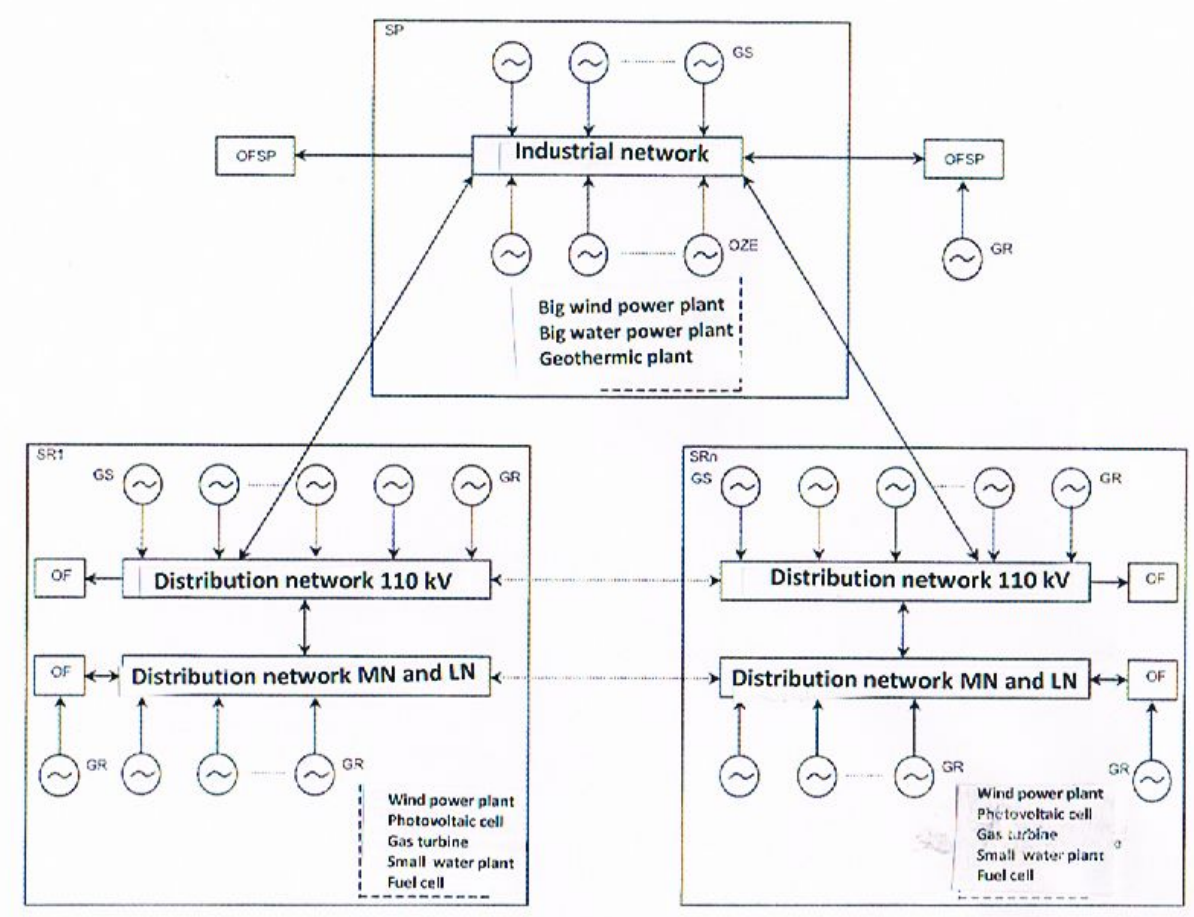

Fig. 2 Scheme of energetic island system configuration.

work of the renewable energy system. Some characteristics properties of photovoltaic energy sources presented on Fig. 3 energetic island system configuration. In practical exploitation of renewable energy sources appears damage work states: short circuits, bad frequency control, bad voltage control during changes of active and reactive power transfer to electric energy system, LVRT - low voltage faults ride through, and also FRT (fault row through) with dynamic grid support, provision of reactive current for highly dynamic voltage control, and also FRT with dynamic grid support. In the paper presented some 


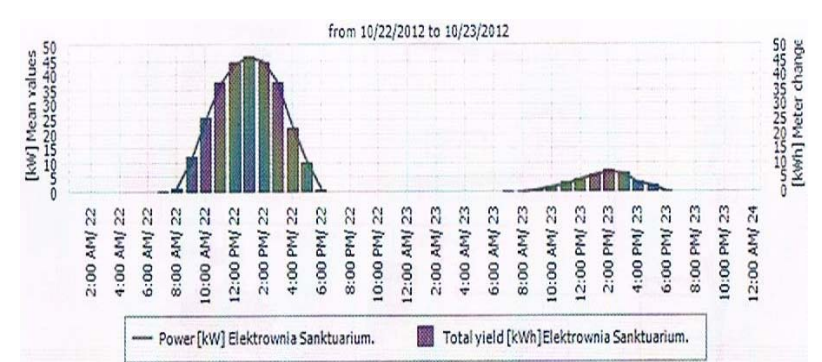

Fig. 3 Changes of power and total yield for PV [1].

examples of damage in renewable supply system, due with the inobservance of obligatory regulations, placed the analysis of damage, and preventive measures from futures.

\section{Renewed Source Variable Speed System}

The decoupled variable speed generation system is equipped in PMG (permanent magnet generator), power electronic $\mathrm{AC} / \mathrm{AC}$ converter and super capacitor energy storage CSC. The AC/AC converter consists of rectifier, a DC/DC step-up converter $\left(\mathrm{L}_{\mathrm{dc}}, \mathrm{T}_{\mathrm{dc}}, \mathrm{D}_{\mathrm{dc}}\right)$, a transistor inverter and output filter $\left(\mathrm{L}_{\mathrm{f}}, \mathrm{C}_{\mathrm{f}}\right)$. Additionally to the DC link is connected a super capacitor energy storage CSC via controlled bidirectional DC/DC converter $\left(\mathrm{C}_{\mathrm{sc}}, \mathrm{L}_{\mathrm{sc}}, \mathrm{T}_{\mathrm{bc}}, \mathrm{T}_{\mathrm{cc}}\right)$. The DC/DC converter, operating as chopper, provides the DC link voltage stabilization when generator operates as variable speed voltage source. The inverter, with output filter, generated an AC sinusoidal three phase voltage. To reduce the voltage drop, a super capacitor energy storage, controlled by reversible DC/DC converter, is applied. The energy storage, made with the super capacitor CSC, delivers an additional transient power to the DC link and it compensates the voltage drop caused by load step at low speed $[3,4]$.

Integration of wind turbine driven generation system to variable speed generation system via DC link is shown in Fig. 4 [4]. The wind turbine generator WG supplies rectifier Rew and load torque of turbine generator is controlled by control of rectified current $I_{d g w}$ by chopper (transistor $\mathrm{T}_{\mathrm{cw}}$, inductor $\mathrm{L}_{\mathrm{cw}}$, diode $\mathrm{D}_{\mathrm{cw}}$ ). The main goal of system is to draw as much as possible energy from the wind turbine. This may be achieved indirectly by control of the $\mathrm{DC}$ bus voltage $\mathrm{V}_{\mathrm{dc}}$ according

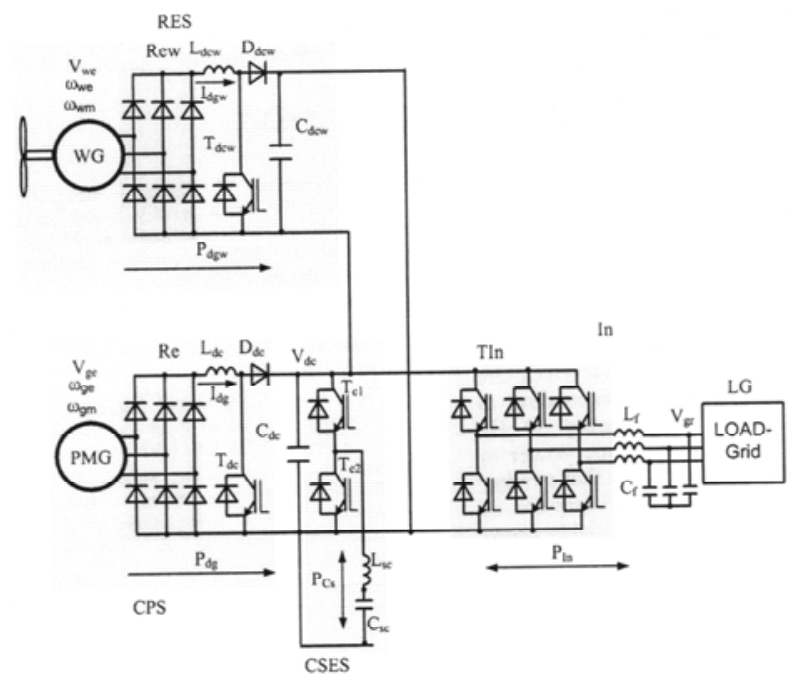

Fig. 4 Scheme of hybrid topology renewed source [3, 4].

to three reference voltages and loads. First reference DC link voltage $V_{\text {dcr1 }}$ is related to the DC voltage produced by chopper of the wind turbine system which is limited and adjusted to wind speed, rectified current $I_{\mathrm{dgw}}$. Its reference current $\mathrm{I}_{\mathrm{dgwr}}$ is produced by the wind turbine controller providing wide speed range operation. The maximum power delivered by wind turbine is $\Delta \mathrm{P}_{\mathrm{dcl} 1 \mathrm{r}}$. Second reference $\mathrm{DC}$ link voltage $\mathrm{V}_{\mathrm{dcr} 2}$ is related to DC voltage, produced by step-up chopper of the variable speed generator controlling rectified current $I_{d g}$, that is set to keep its rated value. To cope with increasing load, the generator speed is rising and when the speed gets its maximum value, then DC link voltage is coming to $\mathrm{V}_{\mathrm{dc}}=\mathrm{V}_{\mathrm{dc} 2 \mathrm{r}}$. The maximum power delivered by the generation system is $\Delta \mathrm{P}_{\mathrm{dc} 2 \mathrm{r}}$. When $\mathrm{V}_{\mathrm{dc}}<\mathrm{V}_{\mathrm{dc} 2 \mathrm{r}}$ then the DC link is supplied by the super capacitor energy storage which is able to deliver maximum power $\Delta \mathrm{P}$. In case of low power, it is produced by the wind turbine $\Delta \mathrm{P}_{\mathrm{dcla}}<\Delta \mathrm{P}_{\mathrm{dc} \text { lr }}$ and low speed of generator $\Delta \mathrm{P}_{\mathrm{dc} 2 \mathrm{a}}<\Delta \mathrm{P}_{\mathrm{dc} 2 \mathrm{r}}[2,5]$. This is a serious advantage of the variable speed generation system over the conventional synchronous generator. However, the low power engine has lower torque which results in longer transients. The longer transients must be compensated by higher energy drawn from the super capacitor. The power delivered to load is a sum of the power delivered by RES and DVSGS. It is advised to the DVSGS to operate continuously with 
minimum power no less than power marked by point $\mathrm{A}$. In this point the engine torque is sufficient high to assure long life of the engine but low speed results in low specific fuel consumption. Change of output voltages and speed in decoupled hybrid system is presented in Fig. 5 [4].

\section{Islanding Detection Methods}

Photovoltaic and solar panel it's devices composed with adequate connected photovoltaic charges, which enable photoelectric phenomenon to generation of electric energy. Basic materials applied to photovoltaic charges construction it different kinds of silicon. Basic part of renewable energy system is microprocessor solar controller. It is apparatus which controls output voltage in optimal point of power consumption work. PWM MPPT (maximum power point tracking) controller enables realization of continuous and ripple charging a solar battery, and protected in damage and faults work conditions. Detecting an islanding condition is the subject of considerable research $[1,3,4$, 6]. It can be classified into passive methods (look for transient events on the grid), and active methods (probe the grid by sending signals of some sort from the inverter or the grid distribution point). There are also methods that utility can use to detect conditions that

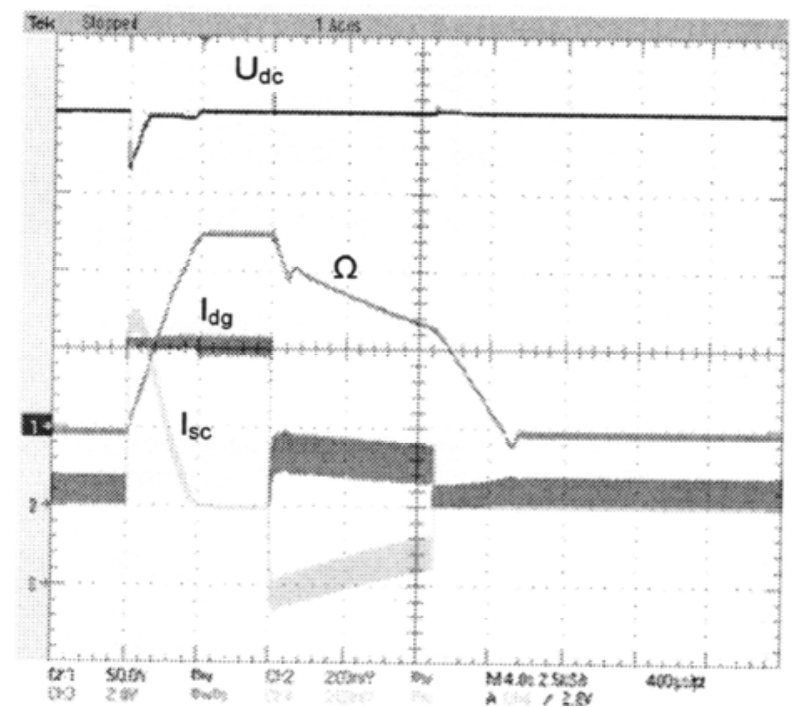

Fig. 5 Change of output voltages and speed in decoupled hybrid system [6]. would cause the inverter-based methods to fail, and deliberately upset those conditions in order to make the inverters switch off. Passive methods include any system that attempts to detect transient changes on the grid, and use that information as the basis as a probabilistic determination of whether or not the grid has failed, or some other condition has resulted in a temporary change. We can use next methods: under/over voltage, under/over frequency, voltage fast jump detection, harmonic detection $[6,7]$.

In under/over voltage method voltage is a function of electrical current and applied load (resistance). In the case of grid interruption, the current being supplied by the local source is unlikely to match the load so perfectly as to be able to maintain a constant voltage. A system that periodically samples voltage and looks for sudden changes can be used to detect a fault condition. Under/over voltage detection is normally trivial to implement in grid-interactive inverters, because the basic function of inverter is to match the grid conditions, including voltage. That means that all grid-interactive inverters, by necessity, have the circuitry needed to detect the changes. All that is needed is an algorithm to detect sudden changes. However, sudden changes in voltage are a common occurrence on the grid as loads are attached and removed, so a threshold must be used to avoid false disconnections. The range of conditions that result in non-detection with this method may be large, and these systems are generally used along with other detection systems. In under/over frequency of the power being delivered to the grid is a function of the supply, one that the inverters carefully match. When the grid source is lost, the frequency of the power would fall to the natural resonant frequency of the circuits in the island. Looking for changes in this frequency, like voltage, is easy to implement using already required functionality, and for this reason almost all inverters also look for fault conditions using this method as well. Unlike changes in voltage, it is generally considered highly unlikely that a random circuit would naturally have a 
natural frequency the same as the grid power. However, many devices deliberately synchronize to the grid frequency, like televisions. Motors, in particular, may be able to provide a signal that is within the NDZ for some time as they "wind down". The combination of voltage and frequency shifts still results in a NDZ that is not considered adequate by all. In voltage phase jump detection method loads generally have power factors that are not perfect, meaning that they generally track the phase of the grid signal using a PLL (phase locked loop) of some sort. The PLL stays in sync with the grid signal by tracking when the signal crosses zero volts. Between those events, the system is essentially "drawing" a sine-shaped output, varying the current output to the circuit to produce the proper voltage waveform. When the grid disconnects, the power factor suddenly changes from the grid's (1) to the load's $(\sim 1)$. As the circuit is still providing a current that would produce a smooth voltage output given the known loads, this condition will result in a sudden change in voltage. By do not accept the voltage from the grid perfectly, but impede it slightly. Grid-tie inverters, by definition, have power factors of 1 . This can lead to changes in phase when the grid fails, which can be used to detect islanding. Inverters the time the waveform is completed and returns to zero, the signal will be out of phase. During harmonics detection method application even with noisy sources, like motors, the THD (total harmonic distortion) of a grid-connected circuit is generally un measurable due to the essentially infinite capacity of the grid that filters these events out. Inverters, on the other hand, generally have much larger distortions, as much as 5\% THD. This is a function of their construction, some THD is a natural side-effect of the switched-mode power supply circuits most inverters are based on. Thus, when the grid disconnects, the THD of the local circuit will naturally increase to that of the inverters themselves. This provides a very secure method of detecting islanding, because there are generally no other sources of THD that would match that of the inverter. Additionally, interactions within the inverters themselves, notably the transformers, have non-linear effects that produce unique 2nd and 3rd harmonics that are easily measurable. The drawback of this approach is that some loads may filter out the distortion, in the same way that the inverter attempts to. If this filtering effect is strong enough, it may reduce the THD below the threshold needed to trigger detection. Systems without a transformer on the "inside" of the disconnect point will make detection more difficult. However, the largest problem is that modern inverters attempt to lower the THD as much as possible, in some cases to un measurable limits. Active methods generally attempt to detect a grid failure by injecting small signals into the line, and then detecting whether or not the signal changes [2, 5].

We can also apply different method concerned with: impedance measurements, slip mode frequency shift, impedance measurements for particular frequency, and frequency bias [8-10], realized in manual or automated disconnection. Fig. 6 presents a low voltage faults ride time function realized during faults works state, and Fig. 7 presents a fault ride in dynamic grid support provision of reactive current for highly dynamic voltage control. During impedance measurement attempts measured overall impedance of the circuit supply from inverter. Normally, it isn't effect on the measured voltage, as the grid is an effectively infinitely stiff voltage source. In the event of a disconnection, even the small forcing would result in a noticeable change in voltage, allowing detection of the island. The main application of this method is a small change for single inverter. However, main weakness of this method; in the case of multiple inverters, each one would be supplying a slightly different signal, hiding the effects on any one inverter. Manual disconnection could be automated through the use of signals sent though the grid, or on secondary means. For instance, power line carrier communications could be installed in all inverters, periodically checking for signals from the utility and disconnecting either on command, or if 


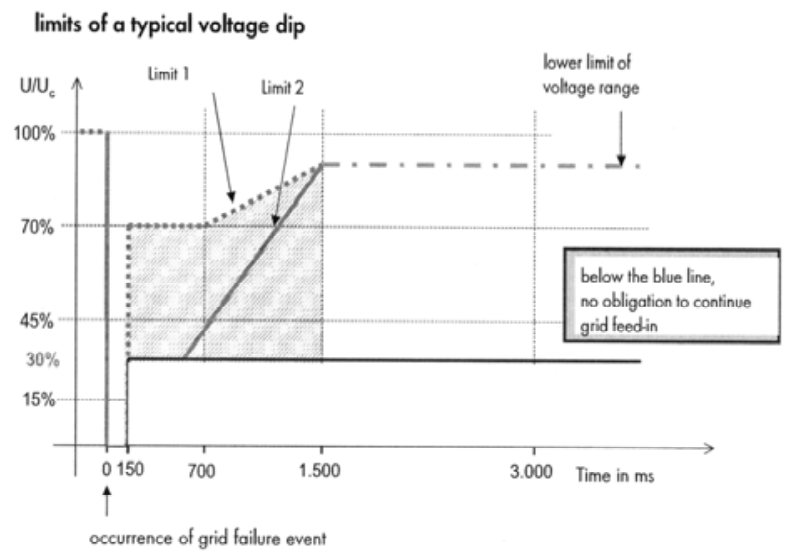

Fig. 6 Time function of low voltage faults ride [2].

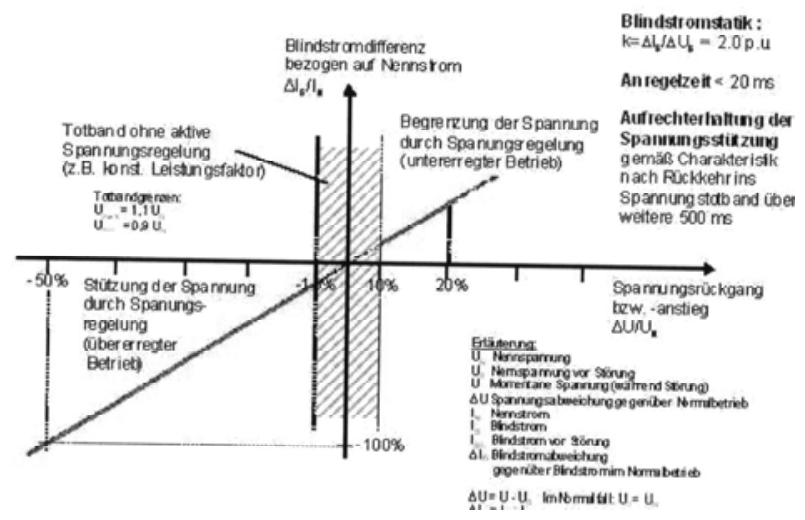

Fig. 7 Fault ride in dynamic grid support [8].

the signal disappears for a fixed time. Such a system would be highly reliable, but expensive to implement. A related concept is to deliberately force a section of the grid into a condition that will guarantee the DG systems will disconnect.

This is similar to the transfer-trip method, but uses active systems at the head-end of the utility, as opposed to relying on the topology of the network. A simple example is a large bank of capacitors that are added to a branch, left charged up and normally disconnected by a switch. In the event of a failure, the capacitors are switched into the branch by the utility after a short delay. This can be easily accomplished through automatic means at the point of distribution. The capacitors can only supply current for a brief period, ensuring that the start or end of the pulse they deliver will cause enough of a change to trip the inverters. There appears to be no NDZ for this method of anti-islanding. Its main disadvantage is cost; the capacitor bank has to be large enough to cause changes in voltage that will be detected, and this is a function of the amount of load on the branch. In theory, very large banks would be needed, an expense the utility is unlikely to look on favourably. Anti-islanding protection can be improved through the use of the SCADA (Supervisory Control and Data Acquisition) systems already widely used in the utility market. For instance, an alarm could sound if the SCADA system detects voltage on a line where a failure is known to be in progress. This does not affect the anti-islanding systems, but may allow any of the systems noted above to be quickly implemented.

\section{Simulation Results and Laboratory Experiments}

Some simulation models were prepared for different kind of renewed and alternative energy source, in application of Matlab Simulink and Simulation X computer program software $[1,6,7]$. In analysis realized a computer simulation of series and parallel

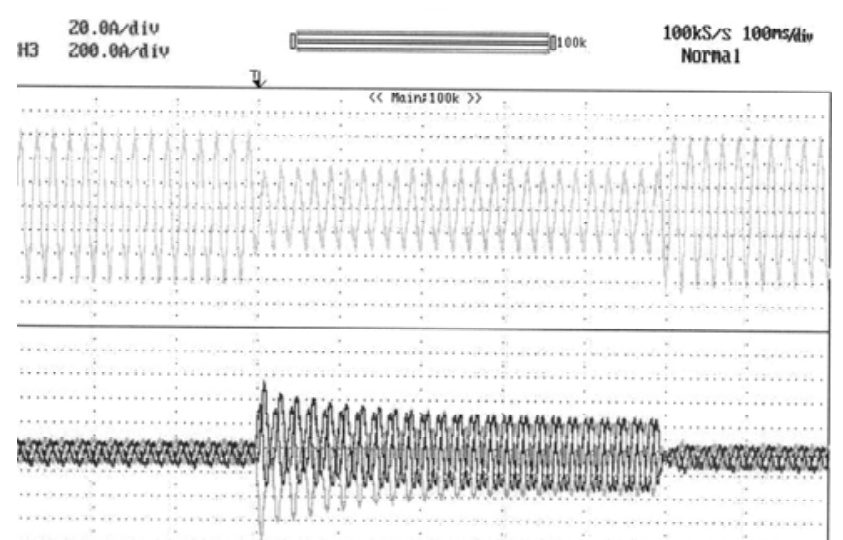

Fig. 8 Change of voltage dip and reactive current during dynamic grid support [1].

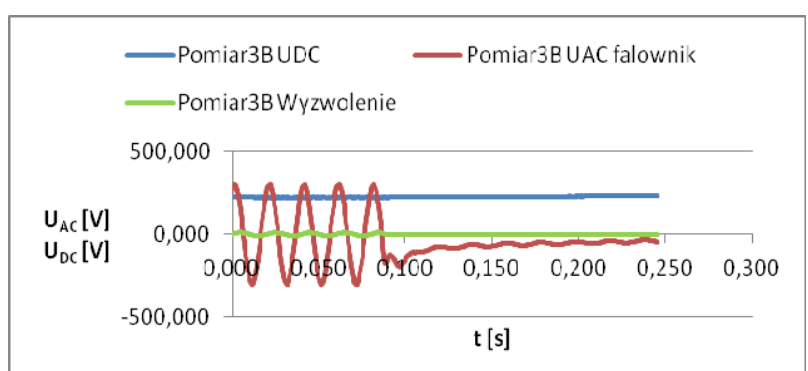

Fig. 9 Change of inverter output voltage during short circuit. 
connected renewed source contained: wind turbine bank, sun batteries charges, fuel combustion engine drives a permanent magnet generator, cooperative with super capacitor and transistor inverter. Results of computers calculations were verified partially laboratory experiments. Fig. 8 presents change of voltage during dip (for one phase visible) and reactive current for voltage support during dynamic grid support, and Fig. 9 presents change of inverter output voltage during short circuit. Laboratory experiments and industrial test confirmed correctness work state of protection system for different faults states.

\section{Conclusion}

The paper presents hybrid generation system made from renewable energy source and decoupled variable speed generation system. The decoupled variable speed generation system operates as conditioner, which delivers power, when the renewable energy source power is not sufficient. It is proposed to arrange common DC link for the renewable energy source and decoupled generation system. The simple decoupled variable speed generation system is perfect conditioner because it delivers power along high efficiency of driving engine. This operation is specially advantaged when changes of the load are related not to steps of rated power. However, when high steps of load power are applied, then an additional conditioner made from super capacitor and DC/DC converter is proposed. The super capacitor is a source of transient high power and is recharged after end of transient state with low current.

\section{References}

[1] Invest in Poland Apax Consulting Group: Renewable energy in Poland, Warsaw, November, 2009.

[2] Heitmann, N. 2005. "Solution of Energy Problems with the Help of Linear Programming." Master thesis, University of Augsburg.

[3] Moskwa, M. 2006. "Parallel Operations of Power Electronic Generator Sets with Alternating Output Voltage." Ph.D. thesis, Warsaw, Poland, Warsaw University of Technology.

[4] Koczara, W., Dziuba, R., Leonarski, J., and Al-Kayat, N. 2001. "Variable Speed Set for Embedded Power Generation." In Proceedings of IEEE 8th International Conference on Electrical Power Quality and Utilization, Cracow, Poland.

[5] Haase, T. 2006. "Anforderung an eine durch Erneuerbare Energien gesprägte Energieversorgung- Untersuchung des Regelverhaltens von Kraftwerken und Verbundnetzen, Dissertaion." Ph.D. dissertation, Faculty of Electrical Engineering, University of Rostock.

[6] Chandorkar, M. C., Divan, D. M. and Adapa, R. 1991. "Control of Parallel Connected Inverters in Stand-alone AC Supply Systems." Presented at Industry Applications Society Annual Meeting, 1003-9.

[7] Divan, D. M., and Chandorkar, M. C. 1997. Method and apparatus for decentralized signal frequency restoration in a distributed UPS system. United States Patent 5,596,492.

[8] Heitmann, N., and Hamacher, Th. 2008. "Stochastic Model of German Electricity System." In Optimization in the Energy Industry, Energy Systems. Berlin, Springer, 365-85.

[9] Han, W. E., and Ward, D. J. 2007. Final Report on EFDA TIMES Model Electricity Sector Update Task. Technical report, UK: EURATOM/UKAEA Fusion Association.

[10] Perreault, D. J., and Kassakian, J. G. 1997. "Distributed Interleaving of Paralleled Power Converters." IEEE Transactions on Circuits and Systems I: Fundamental Theory and Applications 44 (8): 728-34. 